\title{
The Energy of Charge-Transfer States in Electron Donor-Acceptor Blends: Insight into the Energy Losses in Organic Solar Cells
}

\author{
By Dirk Veldman, Stefan C. J. Meskers, and René A. J. Janssen*
}

Here, a general experimental method to determine the energy $E_{\mathrm{CT}}$ of intermolecular charge-transfer (CT) states in electron donor-acceptor (D-A) blends from ground state absorption and electrochemical measurements is proposed. This CT energy is calibrated against the photon energy of maximum CT luminescence from selected D-A blends to correct for a constant Coulombic term. It is shown that $E_{C T}$ correlates linearly with the open-circuit voltage $\left(V_{\text {oc }}\right)$ of photovoltaic devices in D-A blends via $e V_{\text {oc }}=E_{\mathrm{CT}}-0.5 \mathrm{eV}$. Using the CT energy, it is found that photoinduced electron transfer (PET) from the lowest singlet excited state $\left(S_{1}\right.$ with energy $\left.E_{\mathrm{g}}\right)$ in the blend to the $\mathrm{CT}$ state $\left(\mathrm{S}_{1} \rightarrow \mathrm{CT}\right)$ occurs when $E_{\mathrm{g}}-E_{\mathrm{CT}}>0.1 \mathrm{eV}$. Additionally, it is shown that subsequent charge recombination from the CT state to the lowest triplet excited state $\left(E_{T}\right)$ of $D$ or $A\left(C T \rightarrow T_{7}\right)$ can occur when $E_{\mathrm{CT}}-E_{\mathrm{T}}>0.1 \mathrm{eV}$. From these relations, it is concluded that in D-A blends optimized for photovoltaic action: $i$ ) the maximum attainable $V_{\text {oc }}$ is ultimately set by the optical band gap $\left(e V_{o c}=E_{g}-0.6 \mathrm{eV}\right)$ and ii) the singlet-triplet energy gap should be $\Delta E_{\mathrm{ST}}<0.2 \mathrm{eV}$ to prevent recombination to the triplet state. These favorable conditions have not yet been met in conjugated materials and set the stage for further developments in this area. value for the open-circuit voltage $\left(V_{\mathrm{oc}}\right) \cdot{ }^{[1-3]}$ Future, highly efficient organic solar cells therefore will have a high energy CT state that is formed and subsequently dissociates into free electrons and holes with high efficiency.

Despite the importance of CT states for photovoltaic cells their direct spectral identification has only been achieved in a limited number of examples. ${ }^{[4-12]}$ As a direct consequence, the energy of the CT state is often not known and, hence, the minimal energy losses that occur in organic solar cells during the electron transfer from the photoexcited donor or acceptor to the CT state and subsequently to $V_{\text {oc }}$ have not been determined in general. Minimization of photon energy losses, without compromising on the fraction of charge carriers collected per absorbed photon-the internal quantum efficiency (IQE) - is, however, crucial in optimizing the power conversion efficiency $\eta\left(\propto V_{\text {oc }}\right)$ for a given $E_{\mathrm{g}}$. To reduce the loss in photon

\section{Introduction}

Charge-transfer (CT) excitons are weakly bound electron-hole pairs at the interface of an electron donating (D) and an electron accepting (A) material that are populated via photoinduced electron transfer (PET) after excitation of D or A, provided that the $\mathrm{CT}$ exciton energy is lower than the optical band gap energy $\left(E_{\mathrm{CT}}<E_{\mathrm{g}}\right)$, where $E_{\mathrm{g}}$ is the lowest energy of $E_{\mathrm{g}}(\mathrm{D})$ and $E_{\mathrm{g}}(\mathrm{A})$ to assure that electron transfer rather than energy transfer occurs. CT excitons have an important role in the operation of organic solar cells because they are a precursor state to free charge carriers. For the operation of an organic solar cell, the quantum efficiency of CT formation after photon absorption and its subsequent dissociation determine the short-circuit current under illumination, while the CT state energy sets a maximum

[*] Prof. R. A. J. Janssen, Dr. D. Veldman, Dr. S. C. J. Meskers Molecular Materials and Nanosystems

Eindhoven University of Technology

PO Box 513, 5600 MB Eindhoven (The Netherlands)

E-mail: r.a.j.janssen@tue.nl

DOI: $10.1002 / \mathrm{adfm} .200900090$ energy $\left(E_{\mathrm{g}}-e V_{\mathrm{oc}}\right)$, the driving force for PET $\left(-\Delta G_{\mathrm{CT}}=E_{\mathrm{g}}-E_{\mathrm{CT}}\right.$, Fig. 1) should be minimized. Presently, single junction organic photovoltaic cells with the best reported efficiencies have $E_{\mathrm{g}}-e V_{\mathrm{oc}}=0.7-1.1 \mathrm{eV}$ (Table 1). ${ }^{[13-20]}$ Although these photon energy losses are larger than those occurring in the most efficient crystalline inorganic photovoltaic cells based on $\mathrm{Si}$, GaAs, copper indium gallium diselenide (CIGS), InP, or $\mathrm{GaInP}_{2}$ with losses of only $E_{\mathrm{g}}-e V_{\mathrm{oc}}=0.34-0.48 \mathrm{eV},^{[21-28]}$ not much is known about the minimal photon energy losses for organic solar cells, ${ }^{[2,29,30]}$ nor to what extent the driving force of the PET step $-\Delta G_{\mathrm{CT}}$ contributes.

In the natural photosynthetic reaction system, the first electron transfer step from the photoexcited special pair $\mathrm{BChl}_{2}{ }^{*}$ to pheophytin $\mathrm{BPh}$ occurs within ca. 3 ps with $-\Delta G_{\mathrm{CT}}=0.25 \mathrm{eV}^{[31]}$ For a linear perylenemonoimide-perylenediimide electron donor-acceptor (D-A) model system in solution a driving force of $-\Delta G_{\mathrm{CT}}=$ ca. $0.1 \mathrm{eV}$ is enough to effectively deactivate the $\mathrm{S}_{1}$ excited state of the molecule, leading to a 100 -fold photoluminescence quenching of the $S_{1}$ state. ${ }^{[32]}$ Both examples show that in solution small values for $-\Delta G_{\mathrm{CT}}$ suffice for the effective depopulation of charge neutral excited states.

The difficulty in determining $-\Delta G_{\mathrm{CT}}$ for solid state D-A blends lies in establishing $E_{\mathrm{CT}}$. Ground state CT complex absorption and CT emission intensities of D-A blends are 


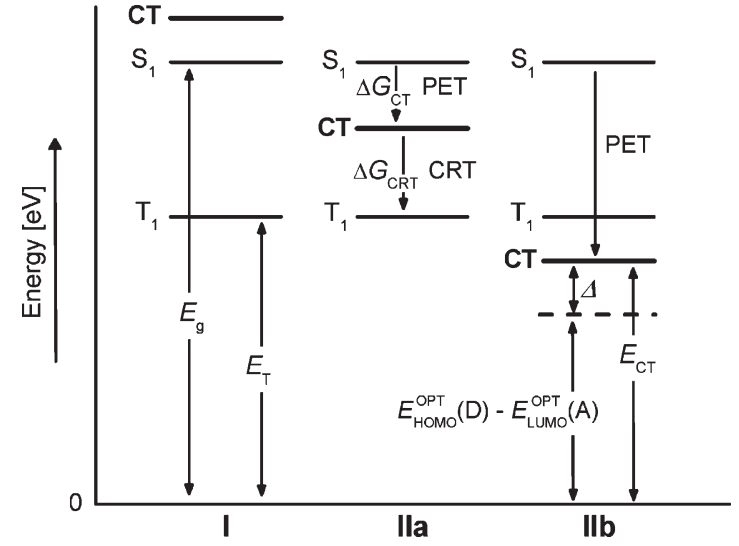

Figure 1. Energy diagram showing three possible arrangements of the lowest singlet $\left(\mathrm{S}_{1}\right)$, triplet $\left(\mathrm{T}_{1}\right)$, and $C T$ excited states relative to the singlet ground state $\left(\mathrm{S}_{0}\right)$ for D-A blends: Type I represents $\mathrm{D}-\mathrm{A}$ blends in which PET is absent because the CT state is situated at an energy higher than the lowest $\mathrm{S}_{1}$ state. Types Ila and IIb show situations in which PET does occur: with (Type IIa) and without (Type IIb) charge recombination to the lowest $\mathrm{T}_{1}$ state $(\mathrm{CRT})$. Note that $E_{\mathrm{g}}$ and $E_{\mathrm{T}}$ represent the lowest energies of $E_{\mathrm{g}}(\mathrm{D})$ or $E_{\mathrm{g}}(\mathrm{A})$, and $E_{\mathrm{T}}(\mathrm{D})$ or $E_{\mathrm{T}}(\mathrm{A})$, respectively.

generally much weaker than the $\mathrm{S}_{0}-\mathrm{S}_{1}$ transitions of the separate materials. Still, CT absorption, involving absorption from a ground state CT complex to an excited CT state, as well as CT emission, i.e., radiative decay from the CT excited state to the ground state, have been observed for D-A blends using sensitive detection techniques. ${ }^{[4-12]}$

Here, we describe a general-empirical-method to predict $E_{\mathrm{CT}}$ for D-A films using cyclic voltammetry data of the individual components in solution and the energies of the lowest excited singlet state of these components determined from absorption spectroscopy on solid films. The predicted values for $E_{\mathrm{CT}}$ are then used to estimate the minimal $\Delta G_{\mathrm{CT}}$ required for PET using photoluminescence, photoinduced absorption, and photovoltaic measurements for a series of 18 different D-A blends based on six electron donors (D1-D6) and nine electron acceptors (A1-A9, Fig. 2), comprising polymer/dye, polymer/fullerene, and polymer/polymer mixtures. From the minimal energy dissipated in the formation of the $\mathrm{CT}$ state $\left(\mathrm{S}_{1} \rightarrow \mathrm{CT}\right)$ an estimate of the energy lost from $E_{\mathrm{CT}}$ to $e V_{\mathrm{oc}}$ is obtained. The results provide evidence that for optimized organic bulk-heterojunction photovoltaic devices the major photon energy-loss results from processes occurring after population of the CT excited state and not in the PET step. Using these results we predict the maximum efficiency for organic solar cells directly from the optical band gap.

Another issue related to $E_{\mathrm{CT}}$ and the performance of organic photovoltaic devices that we will address in the paper is the possibility that the CT excited state recombines into a neutral triplet excited state of one of the two materials $\left(\mathrm{CT} \rightarrow \mathrm{T}_{1}\right)$. Charge recombination to the triplet (CRT) has recently been identified for a number of D-A blends and may represent a significant loss mechanism by reducing the photocurrent. ${ }^{[2,3 c, 7,8,12 \mathrm{~d}, 33,34]}$ This process can occur if the energy of triplet excited state of $\mathrm{D}$ or $\mathrm{A}$ in the active layer is at or below that of the CT state $\left(E_{\mathrm{T}} \leq E_{\mathrm{CT}}\right)$. Hence, this loss mechanism may impact on the performance of devices with high a $V_{\text {oc }}$ (and consequently a high $E_{\mathrm{CT}}$ ) compared to $E_{\mathrm{g}}$. By having established $E_{\mathrm{CT}}$ and knowing $E_{\mathrm{T}}$, we have been able to more accurately establish the energetic conditions for the formation of triplet excited states in D-A blends via recombination of charges.

\section{Methodology}

Oxidation and reduction potentials of $\pi$-conjugated materials can routinely be determined in solution using cyclic voltammetry. ${ }^{[35]}$ The difference between the onsets of the oxidation $\left(E_{\mathrm{ox}}\right)$ and reduction $\left(E_{\text {red }}\right)$ waves defines the electrochemical gap $E_{\mathrm{cv}}^{\mathrm{sol}}=e\left(E_{\mathrm{ox}}-E_{\mathrm{red}}\right)$ that can be compared to the onset of optical absorption in a thin film $\left(E_{\mathrm{g}}\right)$. In first approximation, $E_{\mathrm{cv}}^{\mathrm{sol}}$ and $E_{\mathrm{g}}$ both represent the band gap but they differ for reasons that will be outlined below. We use the experimental difference between $E_{\mathrm{cv}}^{\mathrm{sol}}$ and $E_{\mathrm{g}}$ to estimate "effective" optical HOMO ( $\left.E_{\mathrm{HOMO}}^{\mathrm{OPT}}\right)$ and LUMO $\left(E_{\mathrm{LUMO}}^{\mathrm{OPT}}\right)$ energies of the separate materials in thin solid films. These energies are derived from $E_{\mathrm{ox}}$ and $E_{\text {red }}$ assuming that the difference $E_{\mathrm{cv}}^{\mathrm{sol}}-E_{\mathrm{g}}$ can be equally divided over the HOMO and the LUMO and using a work function value of $-5.23 \mathrm{eV}$ for $\mathrm{Fc} /$ $\mathrm{FC}^{+[36-38]}$

$$
E_{\mathrm{HOMO}}^{\mathrm{OPT}}=-5.23 \mathrm{eV}-e E_{\mathrm{OX}}+\frac{1}{2}\left(E_{\mathrm{cv}}^{\mathrm{sol}}-E_{\mathrm{g}}\right)
$$

Table 1. The optical band gaps of the electron donor $E_{\mathrm{g}}(\mathrm{D})$ and the electron acceptor $E_{\mathrm{g}}(\mathrm{A}), V_{\mathrm{oc}}$, and power conversion efficiency $\eta$ for efficient organic photovoltaic devices.

\begin{tabular}{|c|c|c|c|c|c|c|}
\hline Photovoltaic device & $E_{g}(\mathrm{D})[\mathrm{eV}]$ & $E_{g}(\mathrm{~A})[\mathrm{eV}]$ & $V_{o c}[\mathrm{~V}]$ & $\eta[\%]$ & $E_{\mathrm{g}}-e V_{\mathrm{oc}}[\mathrm{eV}][\mathrm{a}]$ & Ref. \\
\hline PCPDTBT:[70]PCBM & 1.38 & 1.70 & 0.62 & 5.5 & 0.76 & [13] \\
\hline PSiFDBT:[60]PCBM & 1.82 & 1.70 & 0.90 & 5.4 & 0.80 & [14] \\
\hline PSBTBT:[70]PCBM & 1.45 & 1.70 & 0.68 & 5.1 & 0.77 & [15] \\
\hline Р3НT:[60]PCBM & 1.91 & 1.70 & 0.61 & 4.4 & 1.09 & [16] \\
\hline PF 10TBT:[60]PCBM & 1.95 & 1.70 & 1.00 & 4.2 & 0.70 & [17] \\
\hline PBBTDPP2:[70]PCBM & 1.43 & 1.70 & 0.61 & 4.0 & 0.82 & [18] \\
\hline PCDTBT:[60]PCBM & 1.88 & 1.70 & 0.89 & 3.6 & 0.81 & [19] \\
\hline MDMO-PPV:[70]PCBM & 2.10 & 1.70 & 0.77 & 3.0 & 0.93 & [20] \\
\hline
\end{tabular}

[a] Using the lowest value of $E_{\mathrm{g}}(\mathrm{D})$ and $E_{\mathrm{g}}(\mathrm{A})$ for $E_{\mathrm{g}}$. 


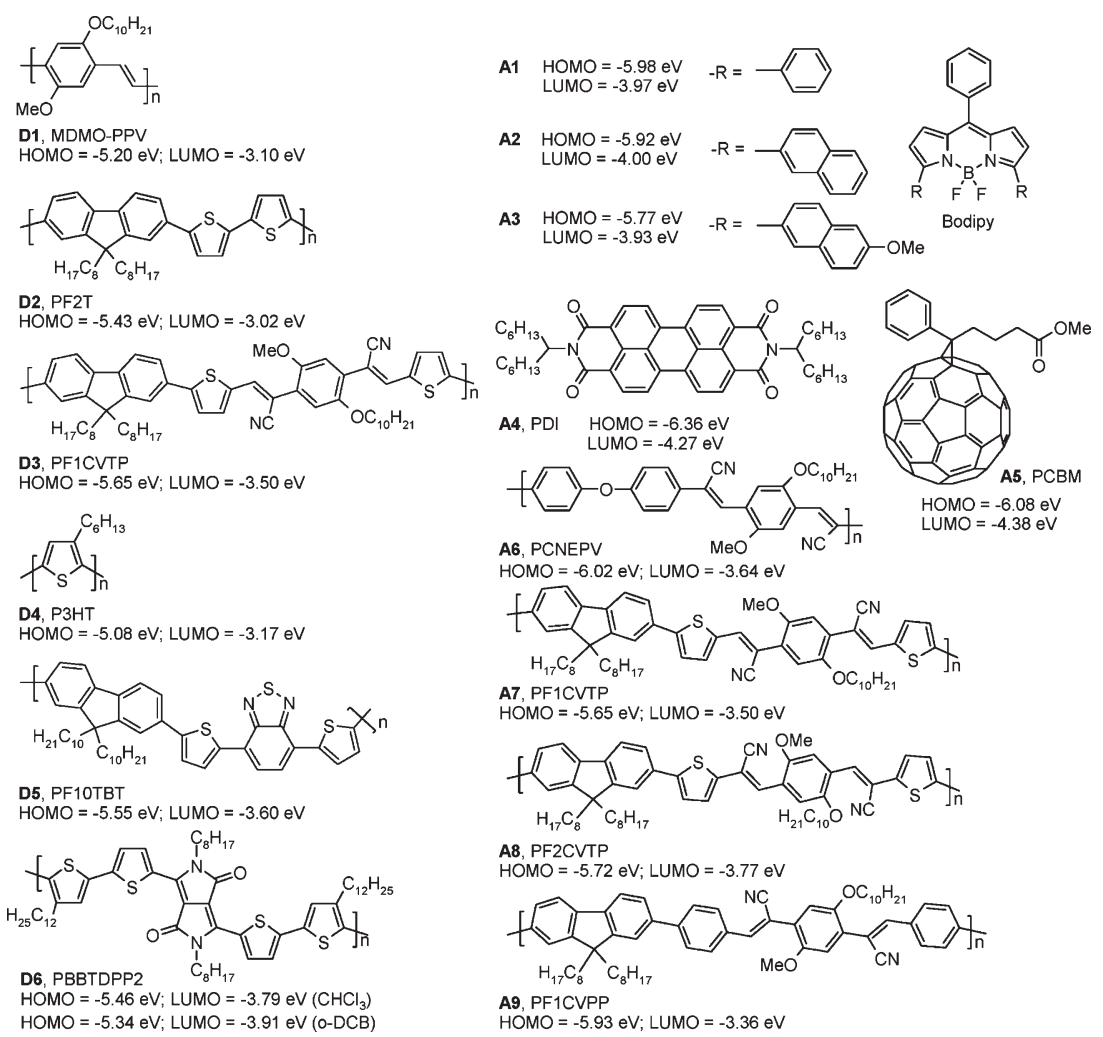

Figure 2. Chemical structures of the electron donating (left, D1-D6) and accepting (right, A1-A9) materials. HOMO and LUMO indicate $E_{\mathrm{HOMO}}^{\mathrm{OPT}}$ and $E_{\mathrm{LUMO}}^{\mathrm{OPT}}$ as defined in Equations (1) and (2). Note that the polymer PF 1CVTP is used both as an electron donor (D3) as well as an electron acceptor (A7)

$E_{\mathrm{LUMO}}^{\mathrm{OPT}}=-5.23 \mathrm{eV}-e E_{\mathrm{red}}-\frac{1}{2}\left(E_{\mathrm{cv}}^{\mathrm{sol}}-E_{\mathrm{g}}\right)$

Note that, by this definition, the "effective" HOMO-LUMO gap $\left|E_{\mathrm{HOMO}}^{\mathrm{OPT}}-E_{\mathrm{LUMO}}^{\mathrm{OPT}}\right|$ of a material (D or $\mathrm{A}$ ) is equal to its optical gap $E_{\mathrm{g}}$, and hence one could argue that these "effective" HOMO and LUMO levels incorporate the intramolecular exciton binding energy in the solid state.

The use of the "effective" HOMO and LUMO levels rather than the oxidation and reduction potential obtained from solution measurements compensates for a number of effects that cause $E_{\mathrm{cv}}^{\mathrm{sol}}$ and $E_{\mathrm{g}}$ to be different:

i) $E_{\text {ox }}$ and $E_{\text {red }}$ typically are determined in a solution with higher relative permittivity (e.g., for o-dichlorobenzene (o-DCB) $\left.\varepsilon_{\mathrm{r}}=10.36\right)$ than that of a conjugated material in a thin film $\left(\varepsilon_{\mathrm{r}} \sim 3-4\right)$, and in the presence of additional electrolyte. These factors cause a considerable gain in solvation energy for an ion in solution, and hence a reduction of $E_{\mathrm{cv}}^{\mathrm{sol}}$ relative to $E_{\mathrm{g}}$.

ii) In a cyclic voltammetry experiment to determine $E_{\text {ox }}$ or $E_{\text {red }}$ electrons are extracted or added but not at the same time. In contrast, $E_{\mathrm{g}}$ provides the energetic difference for an intramolecular, excitonic state, with the hole and the electron stabilized by Coulomb attraction. This causes a reduction of $E_{\mathrm{g}}$ relative to $E_{\mathrm{cv}}^{\mathrm{sol}}$.

iii) Some materials show a strong reduction of their (optical) HOMO-LUMO gap upon going from solution to the (semi)crystalline solid state as a result of chain-chain interactions. This results in $E_{\mathrm{cv}}^{\mathrm{sol}}$ to be higher than $E_{\mathrm{g}}$.

Having defined the "effective" HOMO and LUMO levels, the energy of the intermolecular CT state at the D-A interface can be described as

$$
E_{\mathrm{CT}}=\left|E_{\mathrm{HOMO}}^{\mathrm{OPT}}(\mathrm{D})-E_{\mathrm{LUMO}}^{\mathrm{OPT}}(\mathrm{A})\right|+\Delta
$$

in which $\Delta$ represents a Coulomb term to account for the higher energy of the intermolecular CT exciton compared to an intramolecular exciton due to the larger electronhole separation distance. The driving force for PET from the material with the lowest singlet excited state is equal to

$$
\begin{aligned}
\Delta G_{\mathrm{CT}}= & E_{\mathrm{CT}}-E_{\mathrm{g}} \\
= & \left|E_{\mathrm{HOMO}}^{\mathrm{OPT}}(\mathrm{D})-E_{\mathrm{LUMO}}^{\mathrm{OPT}}(\mathrm{A})\right| \\
& -E_{\mathrm{g}}+\Delta
\end{aligned}
$$

Similarly, the driving force for CRT from the CT state to the material with the lowest triplet excited state energy can be described in terms of the triplet excited state energy of the material with the lowest triplet energy $E_{\mathrm{T}}$ and $E_{\mathrm{CT}}$ (Fig. 1)

$$
\begin{aligned}
\Delta G_{\mathrm{CRT}} & =E_{\mathrm{T}}-E_{\mathrm{CT}} \\
& =E_{\mathrm{T}}-\left|E_{\mathrm{HOMO}}^{\mathrm{OPT}}(\mathrm{D})-E_{\mathrm{LUMO}}^{\mathrm{OPT}}(\mathrm{A})\right|-\Delta
\end{aligned}
$$

\section{Results}

\subsection{The Energy of the CT State}

The optical band gaps of the 18 individual materials in film $\left(E_{\mathrm{g}}\right)$ and solution $\left(E_{\mathrm{cv}}^{\mathrm{sol}}, E_{\mathrm{g}}^{\mathrm{sol}}\right)$ are collected in Table 2 together with values for $E_{\text {ox }}$ and $E_{\text {red }}$. For some materials (e.g., D2-D4, A5, ${ }^{[39]}$ and A9) the electrochemical gap $\left(E_{\mathrm{cv}}^{\mathrm{sol}}\right)$ is larger than the optical gap in solution $\left(E_{\mathrm{g}}^{\mathrm{sol}}\right)$, while for other materials (e.g., D5 and A1A4) $E_{\mathrm{cv}}^{\mathrm{sol}}<E_{\mathrm{g}}^{\mathrm{sol}}$. The small differences between $E_{\mathrm{cv}}^{\mathrm{sol}}$ and $E_{\mathrm{g}}^{\mathrm{sol}}$ ( $0.045 \mathrm{eV}$ on average) indicate that the magnitude of the opposing effects of the lower $\varepsilon_{\mathrm{r}}$ and shorter $\mathrm{e}^{-}-\mathrm{h}^{+}$separation distance in the materials than in cyclic voltammetry measurements are of similar magnitude. $E_{\text {ox }}$ and $E_{\text {red }}$ can be converted to the effective intramolecular HOMO and LUMO energies using Equations (1) and (2) (Fig. 3). On average the correction factor $\frac{1}{2}\left(E_{\mathrm{cv}}^{\mathrm{sol}}-E_{\mathrm{g}}\right)$ is $+0.08 \mathrm{eV}$, varying from $-0.01 \mathrm{eV}$ for $\mathrm{D} 5$ and $\mathrm{A} 3$ to $+0.24 \mathrm{eV}$ for A5 (Table 2). 
Table 2. For all materials the optical band gaps in film and solution $\left(E_{\mathrm{g}}, E_{\mathrm{g}}^{\mathrm{sol}}\right)$, onsets of oxidation and reduction waves $\left(E_{\mathrm{ox}}, E_{\mathrm{red}}\right), E_{\mathrm{cv}}^{\mathrm{sol}}=e\left(E_{\mathrm{ox}}-E_{\mathrm{red}}\right)$, $\left(E_{\mathrm{cV}}^{\mathrm{sol}}-E_{\mathrm{g}}\right) / 2$, the effective HOMO and LUMO levels defined in Equations (1) and (2), and the triplet excited state energies ( $\left.E_{\mathrm{T}}\right)$.

\begin{tabular}{|c|c|c|c|c|c|c|c|c|c|c|}
\hline & & $E_{\mathrm{g}}[\mathrm{eV}]$ & $E_{\mathrm{g}}^{\mathrm{sol}}[\mathrm{eV}]$ & $E_{\mathrm{cV}}^{\mathrm{sol}}[\mathrm{eV}]$ & $E_{\mathrm{ox}}[\mathrm{V}]$ & $E_{\text {red }}[\mathrm{V}]$ & $\left(E_{\mathrm{cv}}^{\mathrm{sol}}-E_{\mathrm{g}}\right) / 2[\mathrm{eV}]$ & $E_{\mathrm{HOMO}}^{\mathrm{opt}}[\mathrm{eV}]$ & $E_{\mathrm{LUMO}}^{\mathrm{opt}}[\mathrm{eV}]$ & $E_{\mathrm{T}}[\mathrm{eV}][\mathrm{a}]$ \\
\hline MDMO-PPV & D1 & 2.10 & 2.20 & 2.21 & 0.02 & -2.19 & 0.05 & -5.20 & -3.10 & 1.40 \\
\hline PF2T & D2 & 2.41 & 2.41 & 2.70 & 0.34 & -2.36 & 0.15 & -5.43 & -3.02 & 1.70 \\
\hline PF1CVTP & D3,A7 & 2.15 & 2.29 & 2.40 & 0.54 & -1.86 & 0.13 & -5.65 & -3.50 & 1.50 \\
\hline P3HT & D4 & 1.91 & 2.25 & 2.36 & 0.07 & -2.29 & 0.23 & -5.08 & -3.17 & 1.40 \\
\hline PF 10TBT & D5 & 1.95 & 1.96 & 1.92 & 0.30 & -1.62 & -0.01 & -5.55 & -3.60 & 1.35 \\
\hline PBBTDPP2 & $\mathrm{DG}_{\mathrm{c}}[\mathrm{b}]$ & 1.67 & 1.72 & 1.65 & 0.22 & -1.43 & -0.01 & -5.46 & -3.79 & 1.00 \\
\hline PBBTDPP2 & D6。 $[b]$ & 1.43 & 1.72 & 1.65 & 0.22 & -1.43 & 0.11 & -5.34 & -3.91 & 0.85 \\
\hline Bodipy 1 & A1 & 2.01 & 2.08 & 2.03 & 0.76 & -1.27 & 0.01 & -5.98 & -3.97 & 1.50 \\
\hline Bodipy 2 & $\mathrm{~A} 2$ & 1.92 & 1.99 & 1.92 & 0.69 & -1.23 & 0.00 & -5.92 & -4.00 & 1.40 \\
\hline Bodipy 3 & $\mathrm{~A} 3$ & 1.84 & 1.90 & 1.82 & 0.53 & -1.29 & -0.01 & -5.77 & -3.93 & 1.30 \\
\hline PDI & A4 & 2.09 & 2.27 & 2.15 & 1.16 & -0.99 & 0.03 & -6.36 & -4.27 & 1.10 \\
\hline PCBM & A5 & 1.70 & 1.72 & 2.17 [c] & 1.08 [c] & -1.09 & 0.24 & -6.08 & -4.38 & 1.50 \\
\hline PCNEPV & A6 & 2.38 & 2.45 & 2.44 & 0.82 & -1.62 & 0.03 & -6.02 & -3.64 & 1.70 \\
\hline PF2CVTP & A8 & 1.95 & 2.07 & 2.09 & 0.56 & -1.53 & 0.07 & -5.72 & -3.77 & 1.30 \\
\hline PF 1CVPP & A9 & 2.57 & 2.69 & 2.88 & 0.85 & -2.03 & 0.16 & -5.93 & -3.36 & 1.90 \\
\hline
\end{tabular}

[a] See Supporting Information. [b] The subscripts "c" and "o" for D6 denote films spin cast from chloroform and o-DCB, respectively. [c] Using $E_{\mathrm{ox}}=E_{\mathrm{cv}}^{\mathrm{sol}} / e+E_{\mathrm{red}}$ with $E_{\mathrm{cv}}^{\mathrm{sol}}$ from Ref.[39]

Having established $E_{\mathrm{HOMO}}^{\mathrm{OPT}}$ and $E_{\mathrm{LUMO}}^{\mathrm{OPT}}$ we can correlate these energies to $E_{\mathrm{CT}}$ and thereby estimate the (average) value for $\Delta . E_{\mathrm{CT}}$ can be determined when the CT state radiatively decays to the ground state. Such CT emission was observed in blends of MDMO-PPV (D1) with three polymer acceptors (A6-A8) where the CT emission shifts to lower energy from $E_{\mathrm{CT}}=1.93 \mathrm{eV}$ to $1.75 \mathrm{eV}$ in the order PF1CVTP (A7), PCNPEV (A6), and PF2CVTP (A8) (Table 3). ${ }^{[2]}$ Also for PF10TBT:PCBM blends (D5:A5) CT emission was observed, at $E_{\mathrm{CT}}=1.50 \mathrm{eV}^{[8]}$ We note that $\mathrm{CT}$ emission is only observed for CT states with a relatively high energy $(>1.4 \mathrm{eV})$. In such case, the (usually weak) CT emission can be observed with a (red) sensitive photomultiplier. For systems with a lower $E_{\mathrm{CT}}$, this emission is more difficult to detect and maybe even weaker in intensity due to faster radiationless decay at low energies. The difference between $E_{\mathrm{CT}}$ of these blends and the effective (intramolecular) electron D-A HOMO-LUMO

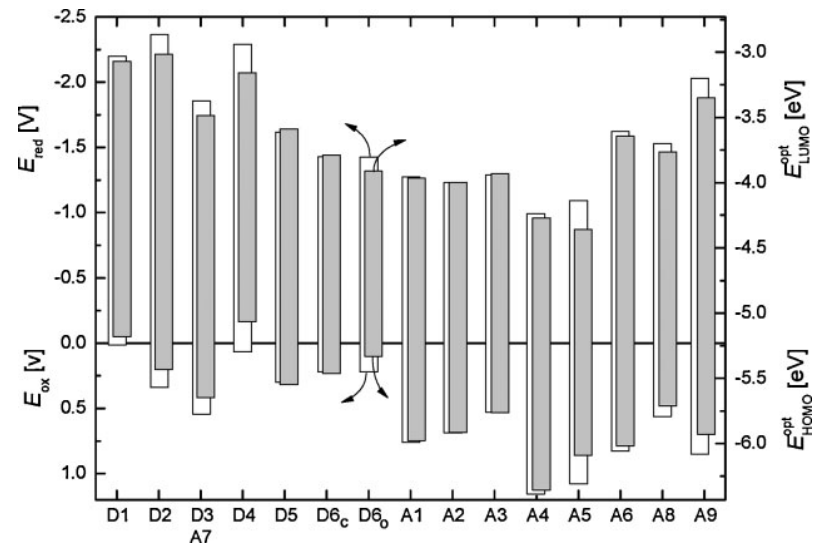

Figure 3. Onset of oxidation and reduction potentials in 0 -DCB (white columns, left axis) versus $\mathrm{Fc}_{\mathrm{Fc}}{ }^{+}$, and effective $\mathrm{HOMO}$ and LUMO energies in thin films (gray columns, right axis) versus vacuum, derived using Equations (1) and (2). The subscripts " $c$ " and "o" for D6 denote films cast from chloroform and o-DCB, respectively. gap $\left|E_{\mathrm{HOMO}}^{\mathrm{OPT}}(\mathrm{D})-E_{\mathrm{LUMO}}^{\mathrm{OPT}}(\mathrm{A})\right|$ provides a measure for $\Delta$ in Equation (3), and we find $\Delta=0.29 \pm 0.02 \mathrm{eV}$ (Fig. 4). Figure 4 also shows that $\left|E_{\mathrm{HOMO}}^{\mathrm{OPT}}(\mathrm{D})-E_{\mathrm{LUMO}}^{\mathrm{OPT}}(\mathrm{A})\right|$ is proportional to the $V_{\text {oc }}$ (Table 3) of photovoltaic devices prepared from these blends $\left[e V_{o c}=\left|E_{H O M O}^{O P T}(D)-E_{L U M O}^{O P T}(A)\right|-0.18( \pm 0.04) \mathrm{eV}\right]$. These relations indicate that for electron $\mathrm{D}-\mathrm{A}$ blends $0.5 \pm 0.1 \mathrm{eV}$ is lost from the excited state energy $E_{\mathrm{CT}}$ to $e V_{\mathrm{oc}}$. Evidently this represents a major loss in energy.

\subsection{Formation and Recombination of CT States}

In this section, we investigate the occurrence or absence of PET $\left(\mathrm{S}_{1} \rightarrow \mathrm{CT}\right)$ and CRT $\left(\mathrm{CT} \rightarrow \mathrm{T}_{1}\right)$ for the $\mathrm{D}-\mathrm{A}$ films. In order to establish whether PET occurs upon photoexcitation of the blends, four criteria have been used. These are:

i) The occurrence of PL quenching of the electron donor as well as the acceptor relative to pristine films.

ii) The fabrication of (rather) efficient photovoltaic devices.

iii) The presence of photoinduced absorption bands of the radical cations in the NIR (e.g., $0.3-1.0 \mathrm{eV}$ for the radical cation of MDMO-PPV, $\mathbf{D} \mathbf{1}^{\bullet+}$ ). We note, however, that the absence of these bands does not preclude PET, because recombination of CT states to triplet excitons may occur.

iv) CT emission

The results are summarized in Table 3 for 18 blends. The blends were categorized in three different types. In Type I blends (4 in total), PET is absent upon photoexcitation. For blends of Type IIa ( 9 in total), PET occurs and is followed by CRT as determined from steady-state photoinduced absorption. ${ }^{[2,8,40]}$ In Type IIb blends ( 5 in total), PET occurs but is not followed by CRT. Experimental details for all blends are given in the Supporting Information but a selected example for each type is discussed below. 
Table 3. Lowest optical band gap $\left(E_{\mathrm{g}}\right)$, triplet excited state energy $\left(E_{T}\right)$, CT state energy $\left(E_{\mathrm{CT}}\right)$, and resulting driving force for PET ( $\left.\Delta G_{\mathrm{CT}}\right)$ and $C R T$ ( $\left.\Delta G_{\mathrm{CRT}}\right)$ for electron D-A blends of different types [a] investigated in this study. Where available, $V_{o c}$ and the spectral maximum of CT emission are given.

\begin{tabular}{|c|c|c|c|c|c|c|c|c|}
\hline & Type & $E_{\mathrm{g}}[\mathrm{eV}]$ & $E_{\mathrm{T}}[\mathrm{eV}]$ & $E_{\mathrm{CT}}[\mathrm{eV}][\mathrm{b}]$ & $\Delta G_{\mathrm{CT}}[\mathrm{eV}][\mathrm{c}]$ & $\Delta G_{\mathrm{CRT}}[\mathrm{eV}][\mathrm{d}]$ & $V_{o c}[\mathrm{~V}]$ & $E_{\mathrm{CT}}[\mathrm{V}][\mathrm{e}]$ \\
\hline D1:A1 & Ila & 2.01 & 1.40 & 1.52 & -0.50 & -0.12 & & \\
\hline D1:A2 & Ila & 1.92 & 1.40 & 1.49 & -0.44 & -0.09 & & \\
\hline D1:A3 & Ila & 1.84 & 1.30 & 1.56 & -0.29 & -0.26 & & \\
\hline D1:A4 & IIb & 2.09 & 1.10 & 1.22 & -0.88 & -0.12 & & \\
\hline D2:A4 & Ila & 2.09 & 1.10 & 1.45 & -0.65 & -0.35 & & \\
\hline D3:A1 & 1 & 2.01 & 1.50 & 1.97 & -0.04 & - & & \\
\hline D3:A2 & I & 1.92 & 1.40 & 1.94 & 0.02 & - & & \\
\hline D3:A3 & 1 & 1.84 & 1.30 & 2.01 & 0.17 & - & & \\
\hline D3:A4 & Ila & 2.09 & 1.10 & 1.67 & -0.43 & -0.57 & & \\
\hline D1:A5 & Ilb & 1.70 & 1.40 & 1.11 & -0.59 & 0.29 & 0.85 & \\
\hline D4:A5 & Ilb & 1.70 & 1.40 & 0.99 & -0.71 & 0.41 & 0.60 & \\
\hline D5:A5 & Ila & 1.70 & 1.35 & 1.46 & -0.24 & -0.11 & 1.00 & 1.50 \\
\hline$(\mathrm{D} 6: \mathrm{A} 5)_{C}[\mathrm{f}]$ & II [g] & 1.67 & 1.00 & 1.38 & -0.30 & -0.37 & 0.78 & \\
\hline$(\mathrm{D} 6: \mathrm{A5}) \mathrm{O}_{\mathrm{O}}[\mathrm{f}]$ & II [g] & 1.43 & 0.85 & 1.26 & -0.18 & -0.40 & 0.63 & \\
\hline D1:A6 & $\mathrm{Ila}$ & 2.10 & 1.40 & 1.85 & -0.26 & -0.45 & 1.38 & 1.85 \\
\hline D1:A7 & Ila & 2.10 & 1.40 & 1.99 & -0.11 & -0.59 & 1.53 & 1.93 \\
\hline D1:A8 & Ila & 1.95 & 1.30 & 1.72 & -0.24 & -0.42 & 1.25 & 1.75 \\
\hline D1:A9 & 1 & 2.10 & 1.40 & 2.13 & 0.03 & - & & \\
\hline
\end{tabular}

[a] The type of blend indicates whether energy transfer (I) or PET is observed (II), followed by CRT (Ila) or not (IIb). [b] From Equation (3) using $\Delta=0.29 \mathrm{eV}$. [c] $\Delta G_{\mathrm{CT}}=E_{\mathrm{CT}}-E_{\mathrm{g}}$. [d] $\Delta G_{\mathrm{CRT}}=E_{\mathrm{T}}-E_{\mathrm{CT}}$. [e] Determined from PL emission maximum. [f] The subscripts "c" and "o" for D6:A5 denote films cast from chloroform and $o-D C B$, respectively. [g] For these films, additional measurements are required to determine whether $T_{1}$ states are populated after PET.

Type I: Photoexcitation of PF1CVPP (A9) in a blend with of MDMO-PPV (D1) results in transfer of excitation energy as a result of the smaller optical band gap of MDMO-PPV (Fig. 5a). Specifically, for blends containing 50 or $95 \mathrm{wt} \%$ D1, near quantitative energy transfer from A9 to D1 occurs with a PL intensity identical to that of a pristine D1 film. The fact that D1 emission is not quenched indicates that the blend is of Type I. Additional evidence for the absence of PET comes from analysis of the PL decay traces of D1 emission at $585 \mathrm{~nm}$ for the 50:50 and 95:5 blends for which the same decay time is found ( $\tau=$ ca. $0.5 \mathrm{~ns}$ ) as for a pristine D1 film (Fig. 5b). Furthermore, the blend does not show any appreciable CT emission, radical cation absorption bands in a PIA experiment, or photovoltaic activity.

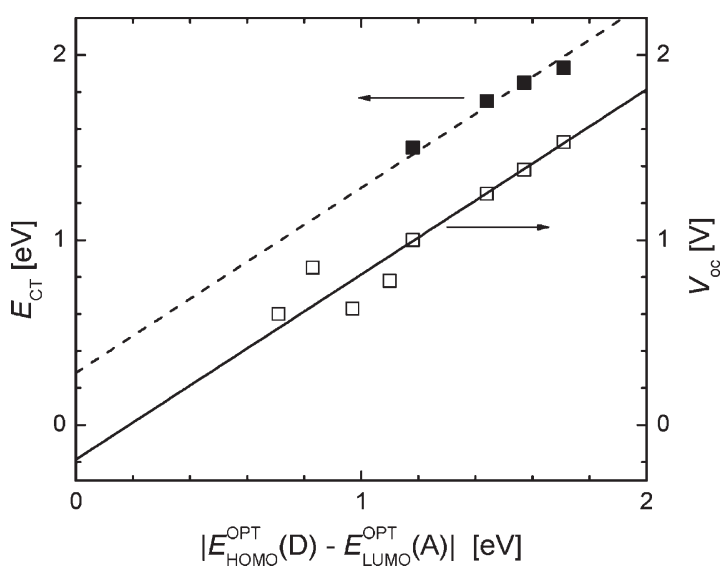

Figure 4. Maximum of $C T$ emission $E_{\mathrm{CT}}$ ( $\square$, left axis) and $V_{\mathrm{oc}}$ ( $\square$, right axis) versus $\left|E_{\mathrm{HOMO}}^{\mathrm{OPT}}(\mathrm{D})-E_{\mathrm{LUMO}}^{\mathrm{OPT}}(\mathrm{A})\right|$. The lines are linear fits through the data with a slope of unity: $E_{\mathrm{CT}}=\left|E_{\mathrm{HOMO}}^{\mathrm{OPT}}(\mathrm{D})-E_{\mathrm{LUMO}}^{\mathrm{OPT}}(\mathrm{A})\right|+0.29( \pm 0.02)$ $\mathrm{eV}$, and $e V_{\mathrm{oc}}=\left|E_{\mathrm{HOMO}}^{\mathrm{OPT}}(\mathrm{D})-E_{\mathrm{LUMO}}^{\mathrm{OPT}}(\mathrm{A})\right|-0.18( \pm 0.04) \mathrm{eV}$.
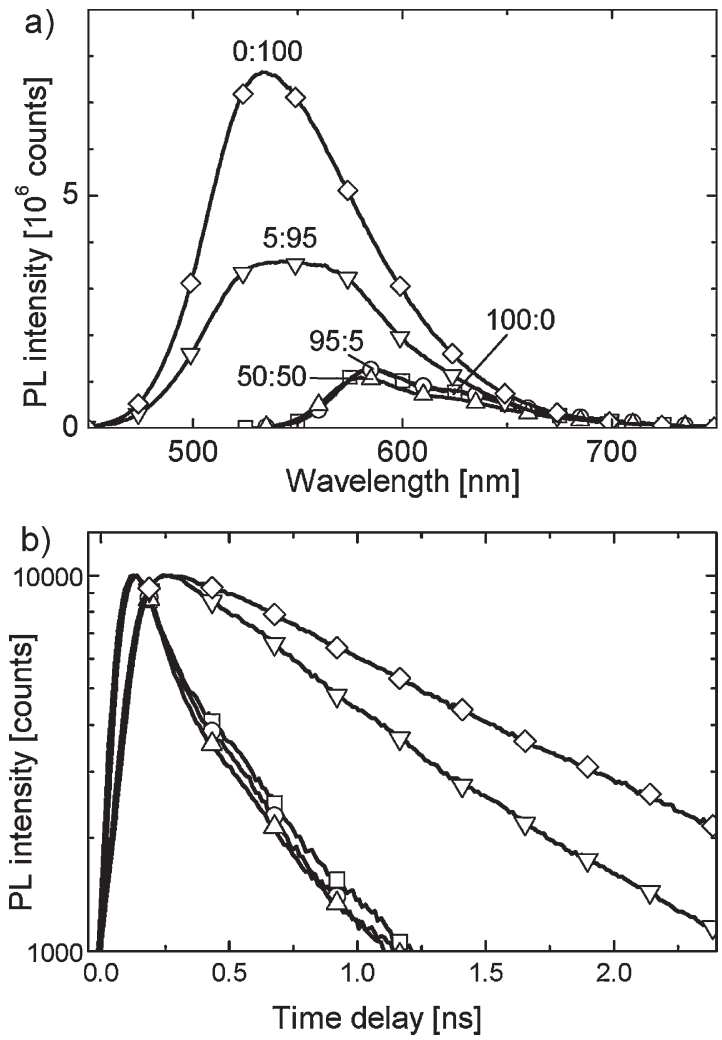

Figure 5. a) PL emission spectra of D1:A9 blends with $0(\square), 5(\bigcirc), 50$ $(\triangle), 95(\nabla)$, and $100(\diamond)$ wt \% of A9. All spectra were corrected for the number of absorbed photons at the excitation wavelength $\left(\lambda_{\text {exc }}=390 \mathrm{~nm}\right)$. For the pristine film of D1, an excitation wavelength of $\lambda_{\text {exc }}=520 \mathrm{~nm}$ was used. b) Time-resolved decay traces of the blends at $585 \mathrm{~nm}$ upon excitation with $\lambda_{\text {exc }}=400 \mathrm{~nm}$. 
Type IIa: For an MDMO-PPV:PF1CVTP (D1:A7) blend evidence for PET comes from complementary studies on efficient photovoltaic devices and PL quenching. Photovoltaic devices have shown efficiencies of $\eta=1.50 \%$ and a maximum external quantum efficiency (EQE) of $52 \%{ }^{[41]}$ while a strong PL quenching of the electron donor and acceptor material has been observed in 1:1 blends relative to pristine donor and acceptor films. ${ }^{[2,41]}$ Further evidence for the occurrence of PET between the two materials comes from the presence of CT emission with a PL maximum at $E_{\mathrm{CT}}=1.93 \mathrm{eV}$ (Table 3). ${ }^{[2]}$ The same study also showed that PET in this blend is followed by CRT to the triplet excited state of D1, as evidenced by higher triplet-triplet absorption intensities of D1 in D1:A7 blends than in a pristine D1 film. ${ }^{[2]}$

Type IIb: The P3HT:PCBM (D4:A5) mixture is a clear example of blends that show PET without subsequent CRT. Efficient photovoltaic devices with power conversion efficiencies up to $5 \%$ and $\mathrm{EQE}=$ ca. $75 \%$ have been obtained for P3HT:PCBM. ${ }^{[42]}$ To achieve such high values for charge carrier extraction, a rapid depopulation of the $S_{1}$ states via efficient PET must occur. This is supported by PL quenching studies that demonstrate PL quenching of the P3HT and PCBM emission for 1:2 blends relative to films
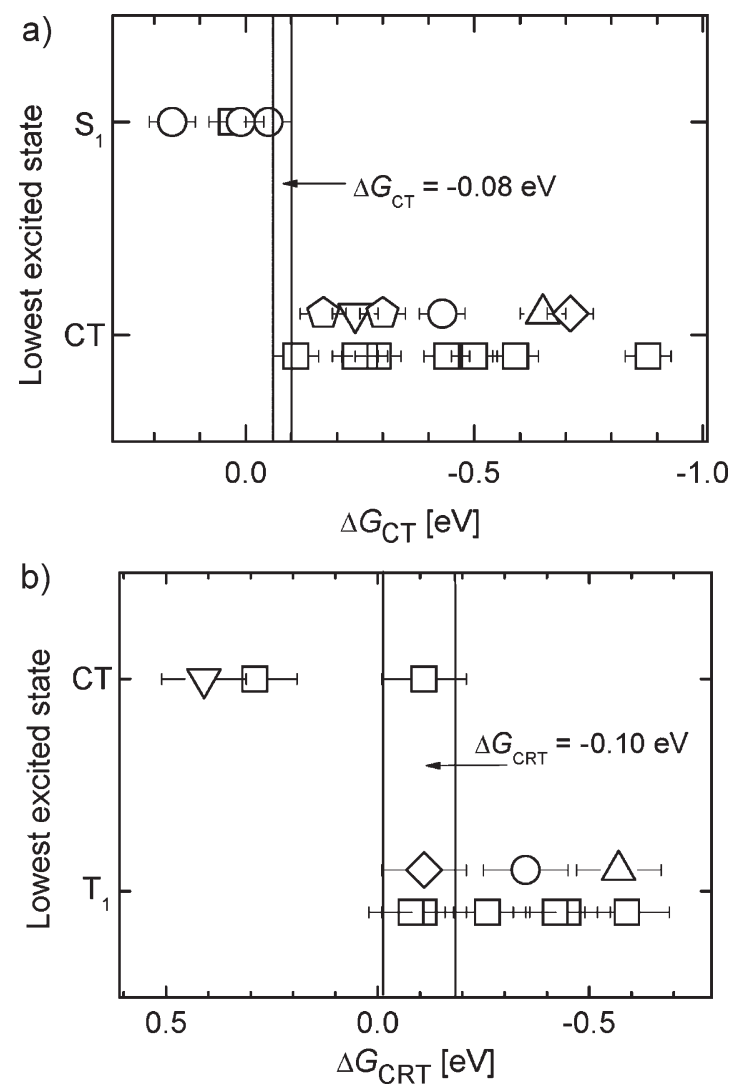

Figure 6. a) Comparison of the occurrence of PET upon photoexcitation of the $18 \mathrm{D}-\mathrm{A}$ blends with $\Delta G_{\mathrm{CT}}$ (Eq. 4 using $\Delta=0.29 \mathrm{eV}$ ). b) Comparison of the occurrence of CRT upon photoexcitation with $\Delta G_{\mathrm{CRT}}$ (Eq. 5 using $\Delta=0.29 \mathrm{eV}$ ) for the $14 \mathrm{D}-\mathrm{A}$ blends that revealed PET. If CRT occurs, $\mathrm{T}_{1}$ is the lowest excited state. If it does not occur, CT is the lowest excited state. The symbols in panels (a) and (b) indicate the different electron donors: D1 $(\square)$, D2 $(\bigcirc)$, D3 $(\triangle)$, D4 $(\nabla)$, D5 $(\diamond)$, and D6 $(\triangle)$. The data with D1 as electron donor which leads to PET and CRT have been given an offset for clarity in (a) and (b), respectively. with higher donor or acceptor content, respectively. ${ }^{[43]}$ Additional evidence for PET results from the presence of polaronic absorption bands in near steady-state photoinduced absorption spectra (see Supporting Information). CRT does not occur, the triplet-triplet absorption intensity of P3HT is strongly quenched and radical cation absorption bands are present in the PIA spectrum at any concentration at or above $0.5 \mathrm{wt} \%$ PCBM.

Having categorized the 18 blends in terms of three different Types (I, IIa, and IIb), we now can correlate the occurrence of PET and of CRT to the energy of the CT state $\left(E_{\mathrm{CT}}\right)$ relative to the optical band gap and triplet state energy, respectively. When using $\Delta=0.29 \mathrm{eV}$ (Section 3.1), we find that a driving force of $-\Delta G_{\mathrm{CT}}=E_{\mathrm{g}}-E_{\mathrm{CT}}=0.08( \pm 0.02) \mathrm{eV}$ between the optical band gap and the CT energy is a minimum value for efficient PET in all 18 blends (Table 3 and Fig. 6a). Similarly, the triplet energies $\left(E_{\mathrm{T}}\right)$ of the materials in the solid state (Table 2 ) can be related to the occurrence of CRT $\left(\mathrm{CT} \rightarrow \mathrm{T}_{1}\right.$ ). Comparing $E_{\mathrm{T}}$ and $E_{\mathrm{CT}}$ for the 14 blends in which PET occurs (Type II), we find that upon photoexcitation higher triplet yields of either of the two materials were observed than in pristine films of the separate materials (Type IIa) when the driving force $-\Delta G_{\mathrm{CRT}}=E_{\mathrm{CT}}-E_{\mathrm{T}}$ equals ca. $0.1 \mathrm{eV}$ or more (Table 3 and Fig. $6 \mathrm{~b}$ ).

\section{Discussion}

In the previous sections, we related $\left|E_{\mathrm{HOMO}}^{\mathrm{OPT}}(\mathrm{D})-E_{\mathrm{LUMO}}^{\mathrm{OPT}}(\mathrm{A})\right|$ for a series of D-A blends to $E_{\mathrm{g}}, E_{\mathrm{T}}, E_{\mathrm{CT}}, V_{\mathrm{oc}}$, and the occurrence of PET and CRT. These results can be combined into a consistent description for the energetics in the D-A blends. Taking the effective HOMO-LUMO gap $\left|E_{\mathrm{HOMO}}^{\mathrm{OPT}}(\mathrm{D})-E_{\mathrm{LUMO}}^{\mathrm{OPT}}(\mathrm{A})\right|$ as an experimental measure, it is observed that:

i) The CT energy in the film is: $E_{\mathrm{CT}}=\mid E_{\mathrm{HOMO}}^{\mathrm{OPT}}(\mathrm{D})-$ $E_{\mathrm{LUMO}}^{\mathrm{OPT}}(\mathrm{A}) \mid+0.29 \mathrm{eV}$ (Fig. 4).

ii) $V_{\mathrm{oc}}$ is given by $e V_{\mathrm{oc}}=\left|E_{\mathrm{HOMO}}^{\mathrm{OPT}}(\mathrm{D})-E_{\mathrm{LUMO}}^{\mathrm{OPT}}(\mathrm{A})\right|-0.18 \mathrm{eV}$ (Fig. 4).

iii) PET occurs when: $\Delta G_{\mathrm{CT}} \leq-0.08$ (Fig. 6a) and, hence, when $E_{\mathrm{g}} \geq\left|E_{\mathrm{HOMO}}^{\mathrm{OPT}}(\mathrm{D})-E_{\mathrm{LUMO}}^{\mathrm{OPT}}(\mathrm{A})\right|+0.37 \mathrm{eV}$.

iv) CRT occurs when $\Delta G_{\mathrm{CRT}} \leq-0.10$ (Fig. 6b) and, hence, when $E_{\mathrm{T}} \leq\left|E_{\mathrm{HOMO}}^{\mathrm{OPT}}(\mathrm{D})-E_{\mathrm{LUMO}}^{\mathrm{OPT}}(\mathrm{A})\right|+0.19 \mathrm{eV}$.

The combined results are summarized in Figure 7, where the energies are rounded to nearest tenth of an $\mathrm{eV}$ to express the experimental uncertainties.

The value of $\Delta=E_{\mathrm{CT}}-\mid E_{\mathrm{HOMO}}^{\mathrm{OPT}}(\mathrm{D})-E_{\mathrm{LUMO}}^{\mathrm{OPT}}(\mathrm{A})=$ ca. $0.29 \mathrm{eV}$ in (i) is determined from a limited number of experiments (involving three polymer/polymer blends and one polymer/ fullerene blend) but corresponds to the value found by Halls et al. for the additional LUMO-LUMO (HOMO-HOMO) offset required between two $\pi$-conjugated polymers in the solid state, to compensate for the increase in the electron-hole potential energy $(\Delta=$ ca. $0.35 \mathrm{eV})$ upon going from an intramolecular excited state of D (A) to an intermolecular CT state with larger electron-hole distance. ${ }^{[44]}$

(iii) shows that a driving force for charge transfer of $-\Delta G_{\mathrm{CT}}=$ ca. $0.1 \mathrm{eV}$ is sufficient to effectively depopulate the lowest singlet excited state $\left(\mathrm{S}_{1} \rightarrow \mathrm{CT}\right)$, while (iv) shows that a driving force of $-\Delta G_{\mathrm{CRT}}=\mathrm{ca} .0 .1 \mathrm{eV}$ is required for charge recombination to triplet excited states. These values are 


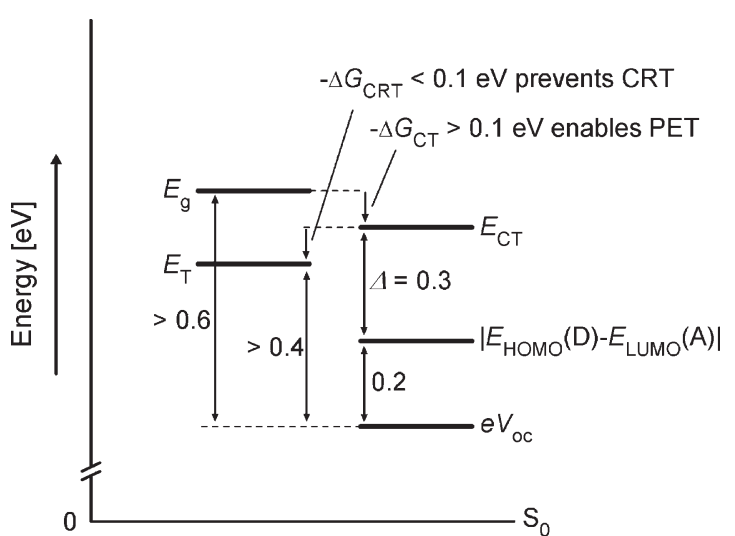

Figure 7. Jablonski diagram with energies of $E_{\mathrm{g}}, E_{\mathrm{T}}, E_{\mathrm{CT}}$, $\left|E_{\mathrm{HOMO}}^{\mathrm{OPT}}(\mathrm{D})-E_{\mathrm{LUMO}}^{\mathrm{OPT}}(\mathrm{A})\right|$, and $e V_{\mathrm{oc}}$ relative to the ground state (rounded to a tenth of an $\mathrm{eV}$ ). The double headed arrow between $V_{\mathrm{oc}}$ and $E_{\mathrm{g}}$ indicates the minimum energy difference for which efficient PET is expected and that between $V_{\mathrm{oc}}$ and $E_{\mathrm{T}}$ the minimum energy difference that prevents CRT.

consistent with the notion that a driving force of $0.1 \mathrm{eV}$ (=ca. $4 \mathrm{k}_{\mathrm{B}} T$ at room temperature) is enough to drive an equilibrium between two excited states towards a $98 \%$ population of the lowest excited state, provided that the lifetimes of the states are longer that the (inverse) rates for interconversion. The estimates for the lower limits of $0.1 \mathrm{eV}$ for $-\Delta G_{\mathrm{CT}}$ and $-\Delta G_{\mathrm{CRT}}$ are correlated to the assumption that the energy of the CT state is given by the maximum of the CT emission. Typically, however, the CT emission is quite broad, which reflects a distribution of CT energies, e.g., as a result of a spread in D-A distances. If the onset of the CT emission would be at $0.1 \mathrm{eV}$ above the CT emission maximum, the minimal $-\Delta G_{\mathrm{CT}}$ for PET would even be less (ca. $0 \mathrm{eV}$ ), while the limit for CRT would be $-\Delta G_{\mathrm{CRT}}=$ ca. $0.2 \mathrm{eV}$. Such an apparent $0.2 \mathrm{eV}$ surplus of driving force for the CRT step compared to the PET step could be explained by an energetic relaxation of CT excitations in time, by hopping to energetically lower lying CT states. This would lead to a lowering of $E_{\mathrm{CT}}$ relative to $E_{\mathrm{T}}$ in time, and hamper CRT. Hence, the actual energy loss in the PET step could even be lower than the $-\Delta G_{\mathrm{CT}}=0.1 \mathrm{eV}$ described above.

Relations (i) and (ii) further imply that the energy loss from $E_{\mathrm{CT}}$ to $e V_{\text {oc }}$ is ca. $0.47 \mathrm{eV}$. This value roughly matches that found recently by Vandewal et al. ${ }^{[9]}$ who obtained the relation $E_{\mathrm{CT}}-e V_{\mathrm{oc}} \approx 0.43 \mathrm{eV}$ from the onset of CT absorption measured by means of Fourier-transform photocurrent spectroscopy (FTPS) for a series of polymer/fullerene blends. Actually, direct comparison of the values for the four blends showing CT emission (Table 3 ) reveals that the difference $E_{\mathrm{CT}}-e V_{\mathrm{oc}}$ falls in the range $0.40-0.50 \mathrm{eV}$.

It is worthwhile to address the origin of the $0.5 \mathrm{~V}$ loss from $E_{\mathrm{CT}} / e$ to $V_{\text {oc }}$. The loss is partly attributed to diffusion of charge carriers into the active layer in the vicinity of the metal electrodes. When Ohmic contacts are applied, selective diffusion of holes (from the ITO/PEDOT:PSS electrode) and electrons (from the $\mathrm{Al} / \mathrm{LiF}$ electrode) into the active layer causes significant band bending in the vicinity of metal contacts, which leads to a reduction of the voltage at which flat band conditions are reached in the bulk of the device. ${ }^{[45]}$ Mihailetchi et al. ${ }^{[45]}$ have shown that for

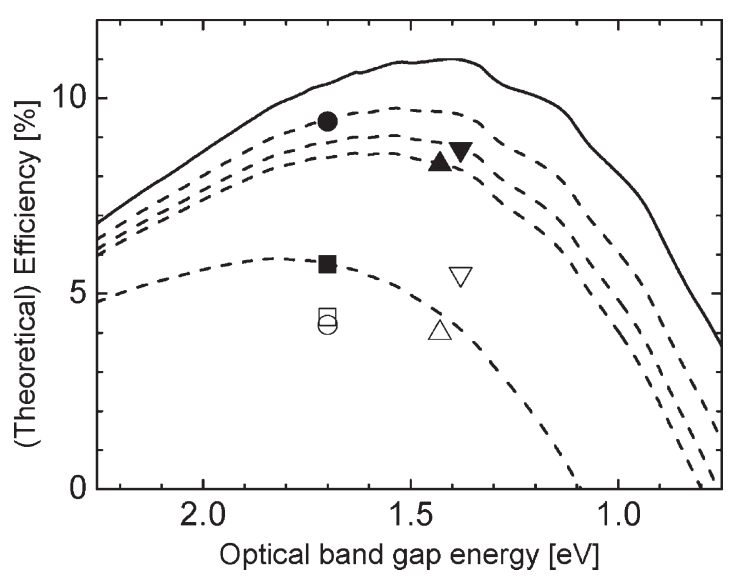

Figure 8. Theoretical efficiency of bulk-heterojunction photovoltaic devices with $E_{\mathrm{g}}-e V_{\text {oc }}=0.60 \mathrm{eV}$ (solid line) versus the lowest optical band gap of the two materials, calculated using the AM1.5 spectrum, FF $=0.65$, and assuming constant $\mathrm{EQE}=0.65$ between $3.5 \mathrm{eV}$ and $E_{\mathrm{g}}$. The dashed lines show the theoretical efficiencies for devices using the larger $E_{\mathrm{g}}-e V_{\mathrm{oc}}$ offsets for (from top to bottom): PF10TBT:[60]PCBM (0.70 eV, ○, O), PCPDTBT:[70]PCBM $(0.76 \mathrm{eV}, \quad \nabla, \quad \nabla), \quad$ PBBTDPP2:[70]PCBM $(0.80 \mathrm{eV}, \boldsymbol{\Delta}, \triangle)$, and P3HT:[60]PCBM (1.09 eV, $\square, \square)$. The closed markers represent the theoretical efficiency, the open markers the reported device efficiencies (Table 1).

an MDMO-PPV:PCBM blend at room temperature, band bending accounts for a $0.38 \mathrm{eV}$ loss from the energy difference between the transport levels $\left(E_{\mathrm{tr}}\right)$ and $e V_{\mathrm{oc}}$. This ca. $0.4 \mathrm{eV}$ difference places $E_{\mathrm{tr}}$ ca. $0.1 \mathrm{eV}$ below $E_{\mathrm{CT}}$ and contributes to efficient collection of electrons and holes at the electrodes. The additional ca. $0.1 \mathrm{eV}$ that is lost from $E_{\mathrm{CT}}$ to $E_{\mathrm{tr}}$ is attributed to be a combination of (i) the balance of Coulomb and polarization energy in the dissociation of CT states in to free carriers, and (ii) the disordered nature of organic semiconductors in general, where the typical width $(\sigma)$ of the density of states is $0.1 \mathrm{eV}^{[45 \mathrm{c}]}$

Finally, when combining (ii) and (iii), it is found that the minimum energy loss for organic (bulk-)heterojunction solar cells compared to lowest optical band gap energy of either D or A amounts to $E_{\mathrm{g}}-e V_{\mathrm{oc}}=\mathrm{ca} .0 .6 \mathrm{eV}$. This value is in accordance with the $V_{\text {oc }}$ found for the most efficient organic solar cells, where $E_{\mathrm{g}}-e V_{\mathrm{oc}}=0.7-1.1 \mathrm{eV}$ (Table 1). ${ }^{[13-20]}$ Schüppel et al. recently came to a similar conclusion for heterojunctions with $\mathrm{C}_{60}$ by studying the photophysical properties of a homologous series of acceptor-substituted oligothiophenes. They found that charge separation on the heterojunction with $\mathrm{C}_{60}\left(E_{\mathrm{g}}=1.7 \mathrm{eV}\right)$ was hampered if $V_{\mathrm{oc}}$ increases above 1.0-1.1 $\mathrm{V}^{[3 \mathrm{c}]}$

If we use $E_{\mathrm{g}}-e V_{\mathrm{oc}}=0.6 \mathrm{eV}$ as the optimum achievable difference between the lowest optical band gap and the open circuit voltage, the maximum power conversion efficiency can be calculated as a function of the lowest optical band gap energy. Considering that photons of the solar spectrum (AM1.5G) with energies at or above $E_{\mathrm{g}}$ are absorbed and that the excess energy of these photons above $E_{\mathrm{g}}$ is lost due to thermalization of hot carriers, we find $\eta=11.0 \%$ for $E_{\mathrm{g}}=1.37-1.45 \mathrm{eV}(855-905 \mathrm{~nm})$ (Fig. 8) when we assume a constant $\mathrm{EQE}=65 \%$ for $E>E_{\mathrm{g}}$ and $\mathrm{a}$ fill factor of $\mathrm{FF}=0.65$. Figure 8 also contains the experimental (open markers) and theoretical (solid markers) efficiencies for selected materials in Table 1. For P3HT:[60]PCBM, the values for the best cells are approaching this theoretical efficiency. However, 
for the other materials combinations the values are still far below the theoretical efficiency. These blends with relatively high CT energy classify as Type IIa. Hence, an explanation for non-optimal device performance could be charge recombination to triplet excited states.

The minimum value of $E_{\mathrm{g}}-e V_{\mathrm{oc}}=0.6 \mathrm{eV}$ that emerges from this work can be compared to the best single junction solar cells to date. The best cells based on inorganic crystalline materials (GaAs, c-Si, CIGS, InP, GaInP $P_{2}$ have $E_{\mathrm{g}}-e V_{\mathrm{oc}}=0.34$ $0.48 \mathrm{eV}^{[21-28]}$ while the best devices from amorphous or nanocrystalline materials (a-Si, nc-Si, CdTe, and dye sensitized cells) have $E_{\mathrm{g}}-e V_{\mathrm{oc}}=0.65-0.80 \mathrm{eV}^{[22,46-49]}$ This supports the idea that disorder in the organic bulk-heterojunction solar cells causes an additional loss with respect to cells prepared from crystalline materials.

\section{Conclusions}

A simple, general method has been established to determine the energy of intermolecular CT states in D-A blends $\left(E_{\mathrm{CT}}\right)$ from UV/ Vis absorption in thin films and electrochemical measurements on the electron donor and the acceptor in solution. By correlating with CT emission it was found that an experimental Coulombic correction term of $\Delta=\mathrm{ca}$. $+0.3 \mathrm{eV}$ must be added to the energy difference between the effective optical HOMO level of the electron donor and the effective LUMO level of the electron acceptor to predict $E_{\text {СT }}$. Knowing the energy of the CT state, it is observed that a minimal driving force of $-\Delta G_{\mathrm{CT}}=E_{\mathrm{g}}-E_{\mathrm{CT}} \geq \mathrm{ca}$. $0.1 \mathrm{eV}$ suffices to effectively populate the CT state in D-A blends from the lowest energy singlet excited state of D or A. Our study furthermore reveals that recombination of $\mathrm{CT}$ states into the lowest $\mathrm{T}_{1}$ state (CRT) occurs if $-\Delta G_{\mathrm{CRT}}=E_{\mathrm{CT}}-E_{\mathrm{T}} \geq$ ca. $0.1 \mathrm{eV}$. This shows that for an optimized organic D-A heterojuction with a minimal offset between the $S_{1}$ and CT energies $\left(-\Delta G_{\mathrm{CT}}=\mathrm{ca}\right.$. $0.1 \mathrm{eV}$ ) a singlet-triplet energy gap of $\Delta E_{\mathrm{ST}}<0.2 \mathrm{eV}$ prevents charge recombination into triplet excited states. This is lower than what is typically found for $\pi$-conjugated polymers $\left(\Delta E_{\mathrm{ST}}=0.5-\right.$ $0.7 \mathrm{eV}$ ), and hence triplet state energies should be considered when designing materials for organic solar cells with minimal $-\Delta G_{\mathrm{CT}}{ }^{[2 \mathrm{CC}]}$ Furthermore, we conclude that in organic bulkheterojunction solar cells ca. $0.5 \mathrm{eV}$ is lost from $E_{\mathrm{CT}}$ to $e V_{\mathrm{oc}}$. Together with the criterion for the minimal $-\Delta G_{\mathrm{CT}}$, this leads to the prediction that for any organic bulk-heterojunction solar cell the maximum attainable $V_{\text {oc }}$ is ultimately set by the lowest optical band gap energy of either donor or acceptor material via $e V_{\mathrm{oc}}=E_{\mathrm{g}}-0.6 \mathrm{eV}$. Presently the best organic solar cells approach this criterion.

\section{Experimental}

Materials: MDMO-PPV was synthesized using the sulfinyl precursor route [50]. PF1CVTP, PF2CVTP, and PF1CVPP [51], PF 10TBT [52], PCNEPV [53,54], the Bodipy dyes (A1-A3) [55], PDI [56], and PBBTDPP2 [57] have been prepared according to the literature procedures. PCBM (Solenne BV) and P3HT (Rieke Metals) were purchased.

Sample Preparation for Optical Spectroscopy: For UV/Vis absorption in solution, samples were prepared by dissolving the materials in o-DCB and heating, if necessary. The samples were measured at room temperature in a cell with $10 \mathrm{~mm}$ optical path length and an optical density of typically 0.5 at the maximum absorption in the visible region of the spectrum. Thin $(50-$ $100 \mathrm{~nm}$ ) films for UV/Vis absorption, steady state and time-resolved photoluminescence ( $\mathrm{PL}$ and TR-PL), and photoinduced absorption were spin cast from chlorobenzene on quartz substrates. Typical solutions contained $1-2 \mathrm{wt} \%$ of material for preparing pristine or composite films. If necessary, the solutions were stirred at elevated temperature prior to spin coating. The film thickness was determined by profilometry (Tencor P-10).

Absorption and Photoluminescence Measurements: UV/Vis absorption and steady-state PL spectra were recorded with a Perkin-Elmer Lambda 900 spectrometer and an Edinburgh Instruments FS920 double-monochromator luminescence spectrometer using a Peltier-cooled red-sensitive photomultiplier, respectively. The fluorescence spectra were corrected for the optical density of the sample at the excitation wavelength, and for the detection sensitivity of the photomultiplier. Time-correlated single photon counting fluorescence studies were performed on an Edinburgh Instruments LifeSpec-PS spectrometer by photoexcitation with a $400 \mathrm{~nm}$ picosecond laser (PicoQuant PDL 800B) operated at $2.5 \mathrm{MHz}$ and detection with a Peltier-cooled Hamamatsu microchannel plate photomultiplier (R3809U-50). Each intensity decay curve was fitted by a multiexponential fit by reconvolution of the instrument response function (IRF) using $I(t)=\int_{-\infty}^{t} I R F\left(t^{\prime}\right) \sum_{i=1}^{n} A_{i} \exp \left[-\left(t-t^{\prime}\right) / \tau_{i}\right] \mathrm{d} t^{\prime}$, where $A_{i}$ is the amplitude of the ith component with a lifetime $\tau_{i}$. The decay parameters were recovered using the software package FluoFit version 4.1 supplied by PicoQuant $\mathrm{GmbH}$, implementing the "nonlinear least-squares" method.

Photoinduced Absorption: Near steady-state photoinduced absorption spectra were recorded between 0.35 and $2.5 \mathrm{eV}$ by excitation at 488 $(2.54 \mathrm{eV})$ or $514 \mathrm{~nm}(2.41 \mathrm{eV})$ with a mechanically modulated $(275 \mathrm{~Hz}) \mathrm{cw}$ argon ion laser pump beam and by measuring the change in transmission of a tungsten-halogen probe beam through the sample $(\Delta T)$ with a phase sensitive lock-in amplifier after dispersion with a monochromator and detection using $\mathrm{Si}$, In GaAs, and cooled InSb detectors. The pump power was typically $25 \mathrm{~mW}$ with a beam diameter of $2 \mathrm{~mm}$. The signal intensity $\left(-\Delta T T^{-1}\right)$ was corrected for the photoluminescence, which was recorded in a separate experiment. Samples were held at $80 \mathrm{~K}$ in an inert nitrogen atmosphere using an Oxford Optistat continuous flow cryostat.

Electrochemistry: Cyclic voltammograms were recorded in an inert atmosphere with $0.1 \mathrm{M}$ tetrabutylammonium hexafluorophosphate $\left(\mathrm{TBAPF}_{6}\right)$ in o-DCB as supporting electrolyte. The working electrode was a platinum disc $\left(0.2 \mathrm{~cm}^{2}\right)$ and the counterelectrode was a platinum electrode. Three different scan speeds were used for all compounds (10, 50 , and $100 \mathrm{mV} \mathrm{s}^{-1}$ ) using a $\mathrm{Ag} / \mathrm{AgCl}$ reference electrode with the ferrocene/ferrocenium couple $\left(\mathrm{Fc} / \mathrm{Fc}^{+}\right)$as an internal standard $(+0.41 \mathrm{eV}$ vs. $\mathrm{Ag} / \mathrm{AgCl}$ in $\mathrm{o}-\mathrm{DCB}$ ) and using a $\mu$ Autolab II with a PGSTAT30 potentiostat. The accuracy of measuring the redox potentials with cyclic voltammetry is about $0.01-0.02 \mathrm{~V}$, reproducibility can be less because the potentials do depend on concentration and temperature.

\section{Acknowledgements}

We thank J. Sweelssen, J. Bastiaansen, B. Langeveld-Voss, M. Koetse (TNO Science and Industry), S. Chopin (TU/e), and M. Turbiez (Ciba Chemicals) for generously providing materials used in this study. This work was supported by the EU Integrated Project NAIMO (no. NMP4-CT-2004500355) and the Interreg Project OLED+. Supporting Information containing information on triplet excited state energies, cyclic voltammetry data, and analyses of photophysical processes is available online from Wiley InterScience or from the authors.

Received: January 17, 2009 Revised: March 4, 2009 Published online:

[1] a) C. J. Brabec, A. Cravino, D. Meissner, N. S. Sariciftci, T. Fromherz, M. T. Rispens, L. Sanchez, J. C. Hummelen, Adv. Funct. Mater. 2001, 11, 374. b) A. Gadisa, M. Svensson, M. R. Andersson, O. Inganas, Appl. Phys. 
Lett. 2004, 84, 1609. c) J. Cremer, P. Bauerle, M. M. Wienk, R. A. J. Janssen, Chem. Mater. 2006, 18, 5832. d) S. Roquet, A. Cravino, P. Leriche, O. Aleveque, P. Frere, J. Roncali, J. Am. Chem. Soc. 2006, 128, 3459. e) K. L. Mutolo, E. I. Mayo, B. P. Rand, S. R. Forrest, M. E. Thompson, J. Am. Chem. Soc. 2006, 128, 8108. f) F. B. Kooistra, J. Knol, F. Kastenberg, L. M. Popescu, W. J. H. Verhees, J. M. Kroon, J. C. Hummelen, Org. Lett. 2007, 9, 551. g) A. Cravino, Appl. Phys. Lett. 2007, 91, 243502.

[2] D. Veldman, T. Offermans, J. Sweelssen, M. M. Koetse, S. C. J. Meskers, R. A. J. Janssen, Thin Solid Films 2006, 511-512, 333.

[3] a) M. C. Scharber, D. Muhlbacher, M. Koppe, P. Denk, C. Waldauf, A. J. Heeger, C. J. Brabec, Adv. Mater. 2006, 18, 789. b) B. P. Rand, D. P. Burk, S. R. Forrest, Phys. Rev. B 2007, 75, 115327. c) R. Schuppel, K. Schmidt, C. Uhrich, K. Schulze, D. Wynands, J. L. Bredas, E. Brier, E. Reinold, H.-B. Bu, P. Bauerle, B. Mannig, M. Pfeiffer, K. Leo, Phys. Rev. B 2008, 77, 085311.

[4] A. C. Morteani, P. Sreearunothai, L. M. Herz, R. H. Friend, C. Silva, Phys. Rev. Lett. 2004, 92, 247402.

[5] a) L. Goris, K. Haenen, M. Nesladek, P. Wagner, D. Vanderzande, L. de Schepper, J. d'Haen, L. Lutsen, J. V. Manca, J. Mater. Sci. 2005, 40, 1413. b) L. Goris, A. Poruba, L. Hod'akova, M. Vanecek, K. Haenen, M. Nesladek, P. Wagner, D. Vanderzande, L. de Schepper, J. V. Manca, Appl. Phys. Lett. 2006, 88, 052113.

[6] J. J. Benson-Smith, L. Goris, K. Vandewal, K. Haenen, J. V. Manca, D. Vanderzande, D. D. C. Bradley, J. Nelson, Adv. Funct. Mater. 2007, 17, 451.

[7] H. Ohkita, S. Cook, Y. Astuti, W. Duffy, S. Tierney, W. Zhang, M. Heeney, I. McCulloch, J. Nelson, D. D. C. Bradley, J. R. Durrant, J. Am. Chem. Soc. 2008, 130, 3030 .

[8] D. Veldman, O. Ipek, S. C. J. Meskers, J. Sweelssen, M. M. Koetse, S. C. Veenstra, J. M. Kroon, S. S. van Bavel, J. Loos, R. A. J. Janssen, J. Am. Chem. Soc. 2008, 130, 7721.

[9] K. Vandewal, A. Gadisa, W. D. Oosterbaan, S. Bertho, F. Banishoeib, I. van Severen, L. Lutsen, T. J. Cleij, D. Vanderzande, J. V. Manca, Adv. Funct. Mater. 2008, 18, 2064.

[10] T. Drori, C.-X. Sheng, A. Ndobe, S. Singh, J. Holt, Z. V. Vardeny, Phys. Rev. Lett. 2008, 101, 037401.

[11] a) K. Hasharoni, M. Keshavarz,-K A. Sastre, R. Gonzalez, C. Bellavia-Lund, Y. Greenwald, J. Chem. Phys. 1997, 107, 2308. b) H. Kim, J. Y. Kim, S. H. Park, K. Lee, Y. Jin, J. Kim, H. Suh, Appl. Phys. Lett. 2005, 86, 183502. c) M. A. Loi, S. Toffanin, M. Muccini, M. Forster, U. Scherf, M. Scharber, Adv. Funct. Mater. 2007, 17, 2111.

[12] a) M. M. Alam, S. A. Jenekhe, J. Phys. Chem. B 2001, 105, 2479. b) X. J. Zhang, D. M. Kale, S. A. Jenekhe, Macromolecules 2002, 35, 382. c) A. C. Morteani, A. S. Dhoot, J.-S. Kim, C. Silva, N. C. Greenham, C. Murphy, E. Moons, S. Cina, J. H. Burroughes, R. H. Friend, Adv. Mater. 2003, 15, 1708. d) T. Offermans, P. A. van Hal, S. C. J. Meskers, M. M. Koetse, R. A. J. Janssen, Phys. Rev. B 2005, 72, 045213. e) T. Kietzke, D. Neher, H.-H. Horhold, Chem. Mater. 2005, 17, 6532. f) S. V. Chasteen, J. O. Haerter, G. Rumbles, J. C. Scott, Y. Nakazawa, M. Jones, H.-H. Horhold, H. Tillmann, S. A. Carter, J. Appl. Phys. 2006, 99, 033709. g) C. Yin, T. Kietzke, D. Neher, H.-H. Horhold, Appl. Phys. Lett. 2007, 90, 092117.

[13] J. Peet, J. Y. Kim, N. E. Coates, W. L. Ma, D. Moses, A. J. Heeger, G. C. Bazan, Nat. Mater. 2007, 6, 497.

[14] E. Wang, L. Wang, L. Lan, C. Luo, W. Zhuang, J. Peng, Y. Cao, Appl. Phys. Lett. 2008, 92, 033307.

[15] J. Hou, H.-Y. Chen, S. Zhang, G. Li, Y. Yang, J. Am. Chem. Soc. 2008, 130, 16144.

[16] G. Li, V. Shrotriya, J. Huang, Y. Yao, T. Moriarty, K. Emery, Y. Yang, Nat. Mater. 2005, 4, 864.

[17] L. H. Slooff, S. C. Veenstra, J. M. Kroon, D. J. D. Moet, J. Sweelssen, M. M. Koetse, Appl. Phys. Lett. 2007, 90, 143506.

[18] M. M. Wienk, M. Turbiez, J. Gilot, R. A. J. Janssen, Adv. Mater. 2008, 20, 2556.

[19] N. Blouin, A. Michaud, M. Leclerc, Adv. Mater. 2007, 19, 2295.

[20] M. M. Wienk, J. M. Kroon, W. J. H. Verhees, J. Knol, J. C. Hummelen, P. A. van Hal, R. A. J. Janssen, Angew. Chem. Int. Ed. 2003, 42, 3317.
[21] R. P. Gale, R. W. McClelland, B. D. King, J. C. C. Fan, Solar Cells 1989, 27, 99.

[22] M. A. Green, K. Emery, Y. Hishikawa, W. Warta, Prog. Photovolt. Res. Appl. 2008, 16, 435.

[23] J. Zhao, A. Wang, M. A. Green, F. Ferrazza, Appl. Phys. Lett. 1998, 73, 1991.

[24] O. Schultz, S. W. Glunz, G. P. Willeke, Prog. Photovolt. Res. Appl. 2004, 12, 553.

[25] M. A. Contreras, B. Egaas, K. Ramanathan, J. Hiltner, A. Swartzlander, F. Hasoon, R. Noufi, Prog. Photovolt. Res. Appl. 1999, 7, 311.

[26] C. J. Keavney, R. J. Walters, P. J. Drevinsky, J. Appl. Phys. 1993, 73, 60.

[27] C.-S. Jiang, H. R. Moutinho, D. J. Friedman, J. F. Geisz, M. M. Al-Jassim, J. Appl. Phys. 2003, 93, 10035.

[28] J. van Deelen, G. J. Bauhuis, J. J. Schermer, P. Mulder, E. J. Haverkamp P. K. Larsen, J. Cryst. Growth 2007, 298, 772.

[29] V. D. Mihailetchi, P. W. M. Blom, J. C. Hummelen, M. T. Rispens, J. Appl. Phys. 2003, 94, 6849.

[30] M. Kemerink, J. M. Kramer, H. H. P. Gommans, R. A. J. Janssen, Appl. Phys. Lett. 2006, 88, 192108.

[31] R. A. Marcus, Angew. Chem. Int. Ed. 1993, 32, 1111.

[32] D. Veldman, S. M. A. Chopin, S. C. J. Meskers, R. A. J. Janssen, J. Phys. Chem. A 2008, 112, 8617.

[33] a) M. C. Scharber, N. A. Schultz, N. S. Sariciftci, C. J. Brabec, Phys. Rev. B 2003, 67, 085202. b) T. A. Ford, I. Avilov, D. Beljonne, N. C. Greenham, Phys. Rev. B 2005, 71, 125212. c) H. Ohkita, S. Cook, Y. Astuti, W. Duffy, M Heeney, S. Tierney, I. McCulloch, D. D. C. Bradley, J. R. Durrant, Chem. Commun. 2006, 3939.

[34] T. A. Ford, H. Ohkita, S. Cook, J. R. Durrant, N. C. Greenham, Chem. Phys. Lett. 2008, 454, 237.

[35] Cyclic voltammetry can also be performed in the solid state. However, we prefer to perform the experiment in o-DCB solution. This has the advantage that the optical absorption and the oxidation and reduction potentials can be measured and compared in the same solvent, for all molecules. Moreover, quality of film formation on the electrode or dissolution of the material from the electrode cannot interfere with the experiment. Additionally, we note that cyclic voltammetry on films may lead to effects associated with the incorporation of cations and anions in the film during the reduction and oxidation. This can influence the measured potentials but is not directly related to the energy levels that one is interested in.

[36] Using a potential value of $4.6 \pm 0.2 \mathrm{eV}$ for NHE versus vacuum (Ref. [37]) and $0.63 \mathrm{eV}$ (Ref. [38]) for $\mathrm{Fc} / \mathrm{Fc}^{+}$versus NHE.

[37] J. O. M. Bockris, S. U. M. Khan, Surface Electrochemistry. A Molecular Level Approach Kluwer Academic/Plenum Publishers, New York 1993.

[38] V. V. Pavlishchuk, A. W. Addison, Inorg. Chim. Acta 2000, 298, 97.

[39] a) R. D. Webster, G. A. Heath, Phys. Chem. Chem. Phys. 2001, 13, 2588. b) C. Bruno, I. Doubitski, M. Marcaccio, F. Paolucci, D. Paolucci, A. Zaopo, J. Am. Chem. Soc. 2003, 125, 15738.

[40] D. Veldman, J. J. A. M. Bastiaansen, B. M. W. Langeveld-Voss, J. Sweelssen, M. M. Koetse, S. C. J. Meskers, R. A. J. Janssen, Thin Solid Films 2006, 511 512, 581.

[41] M. M. Koetse, J. Sweelssen, K. T. Hoekerd, H. F. M. Schoo, S. C. Veenstra, J. M. Kroon, X. Yang, J. Loos, Appl. Phys. Lett. 2006, 88, 083504.

[42] S. Gunes, H. Neugebauer, N. S. Sariciftci, Chem. Rev. 2007, 107, 1324.

[43] Y. Kim, S. A. Choulis, J. Nelson, D. D. C. Bradley, S. Cook, J. R. Durrant, J. Mater. Sci. 2005, 40, 1371.

[44] a) J. J. M. Halls, J. Cornil, D. A. dos Santos, R. Silbey, D. H. Hwang, A. B. Holmes, J. L. Bredas, R. H. Friend, Phys. Rev. B 1998, 60, 5721. b) J. L. Bredas, D. Beljonne, V. Coropceanu, J. Cornil, Chem. Rev. 2004, 104, 4917.

[45] a) J. G. Simmons, J. Phys. Chem. Solids 1971, 32, 1987. b) G. G. Malliaras, J. R. Salem, P. J. Brock, J. C. Scott, J. Appl. Phys. 1998, 84, 1583. c) V. D. Mihailetchi, P. W. M. Blom, J. C. Hummelen, M. T. Rispens, J. Appl. Phys. 2003, 84, 6849. d) M. Kemerink, J. M. Kramer, H. H. P. Gommans, R. A. J. Janssen, Appl. Phys. Lett. 2006, 88, 192108. 
[46] B. E. McCandless, I. Youm, R. W. Birkmire, Prog. Photovolt. Res. Appl. 1999, 7, 21.

[47] K. Yamamoto, M. Yoshimi, Y. Tawada, Y. Okamoto, A. Nakajima, J. NonCryst. Solids 2000, 266-269, 1082.

[48] J. Meier, J. Spitznagel, U. Kroll, C. Bucher, S. Fay, T. Moriarty, A. Shah, Thin Solid Films 2004, 451-452, 518.

[49] M. K. Nazeeruddin, F. de Angelis, S. Fantacci, A. Selloni, G. Viscardi, P. Liska, S. Ito, B. Takeru, M. Grätzel, J. Am. Chem. Soc. 2005, 127, 16835.

[50] L. Lutsen, P. Adriaensens, H. Becker, A. J. van Breemen, D. Vanderzande, J. Gelan, Macromolecules 1999, 32, 6517.

[51] N. S. Cho, D. H. Hwang, B. J. Jung, E. Lim, J. Lee, H. K. Shim, Macromolecules 2004, 37, 5265 .
[52] D. J. D. Moet, L. H. Slooff, J. M. Kroon, S. S. Chevtchenko, J. Loos, M. M. Koetse, J. Sweelssen, S. C. Veenstra, Mater. Res. Soc. Symp. Proc. 2007, 974, 0974-CC03-09.

[53] H. Tillmann, H.-H. Horhold, Synth. Met. 1999, 101, 138.

[54] M. M. Koetse, J. Sweelssen, T. Franse, S. C. Veenstra, J. M. Kroon, X. Yang, A. Alexeev, J. Loos, U. S. Schubert, H. F. M. Schoo, Proc. SPIE Int. Soc. Opt. Eng. 2004, 5215, 119.

[55] A. Burghart, H. Kim, M. B. Welch, L. H. Thoresen, J. Reibenspies, K. Burgess, J. Org. Chem. 1999, 64, 7813.

[56] S. Demmig, H. Langhals, Chem. Ber. 1988, 121, 225.

[57] M. G. R. Turbiez, R. A. J. Janssen, M. M. Wienk, H. J. Kirner, M. Duggli, B. Tieke, Y. Zhu, World Patent Application WO/2008/000664 2008. 